Quim. Nova, Vol. 36, No. 7, 978-983, 2013

\title{
KINETICAL STUDY ABOUT THE COBALT ELECTRODEPOSITION ONTO POLYCRYSTALLINE PLATINUM
}

\author{
Clara Hilda Rios-Reyes \\ Universidad Autónoma del Estado de Hidalgo. Área Académica de Ciencias de la Tierra y Materiales, Mineral de la Reforma, \\ Hidalgo. C.P. 42186, México \\ Luis Humberto Mendoza-Huizar* \\ Universidad Autónoma del Estado de Hidalgo. Área Académica de Química, Mineral de la Reforma, Hidalgo. C.P. 42186, México \\ Víctor Esteban Reyes-Cruz and María Aurora Veloz Rodríguez \\ Universidad Autónoma del Estado de Hidalgo. Área Académica de Ciencias de la Tierra y Materiales, Mineral de la Reforma, \\ Hidalgo. C.P. 42184, México
}

Recebido em 2/10/12; aceito em 25/2/13; publicado na web em 24/5/13

\begin{abstract}
An electrochemical study of Co electrodeposition onto polycrystalline Pt from an aqueous solution containing $10^{-2} \mathrm{M} \mathrm{CoCl}_{2}+$ $1 \mathrm{M} \mathrm{NH}_{4} \mathrm{CI}(\mathrm{pH}=9.3)$ was conducted at overpotential conditions. The current density transients showed two maxima that corresponded to two nucleation and growth processes. The entire transient behavior was adequately predicted considering the contribution to the total current of four different processes: a Langmuir-type adsorption process, a diffusion-controlled twodimensional instantaneous nucleation, and two three-dimensional nucleation and growth processes.
\end{abstract}

Keywords: cobalt; platinum; kinetics.

\section{INTRODUCTION}

Co layers $(\mathrm{CoL})$ on Pt have been synthesized because of their potential to increase stored information in electronic devices. ${ }^{1-7}$ Most CoL have been prepared employing molecular beam sputtering, ${ }^{8}$ evaporation techniques, ${ }^{9,10}$ and more recently, electrodeposition. ${ }^{11-21}$ Although it is well known that electrodeposition contributes to achieving reliable and inexpensive methods to produce $\mathrm{CoL}$ on metallic substrates, ${ }^{22-25}$ to the best of our knowledge, few studies have considered Co electrodeposition on Pt electrodes. ${ }^{11-21}$ Most of these studies have been conducted from sulfate and chloride ammoniacal solutions. ${ }^{11-21}$ Perhaps the main advantage of using chloride plating baths rather than sulfate electrolytes is its higher electrical conductivity at lower overpotentials during Co electrodeposition. ${ }^{12}$ However, the stress added to the Co deposits when using chloride solutions is larger than that when using sulfate solutions. ${ }^{22}$ The complexing property of ammonia can be used to form complex species with Co ions in solution. Here it is important to consider that the $\left(\mathrm{NH}_{4}\right)^{+1}$ ions in solution are bias adsorbed on the negatively charged electrode and deposited Co surface. ${ }^{26}$ Furthermore, the $\left(\mathrm{NH}_{4}\right)^{+1}$ ions may preferentially adsorb on certain orientations, diminishing the growth rate of the Co nucleus. ${ }^{27}$ Also, the presence of $\left(\mathrm{NH}_{4}\right)^{+1}$ ions on the Co coordination sphere diminishes the overpotential applied during cation reduction due to a tunnel effect favored by $\left(\mathrm{NH}_{4}\right)^{+1} \cdot{ }^{23}$

Co electrodeposition on Pt substrates from chloride solutions may not have received much attention because, in such systems, simultaneous hydrogen evolution makes Co electrodeposition difficult. Kongstein et al. reported that proton reduction modifies the reaction mechanism of Co during electrodeposition on Pt from chloride plating baths. ${ }^{12}$ In addition, for a Pt electrode in acidic conditions, when the current density, $\mathrm{pH}$, and temperature are increased, an improvement in the current efficiency of Co deposition is reported. ${ }^{12}$ The current efficiency decreases when the rotating rate of the electrode is augmented. ${ }^{13}$ Although such studies are important for the development of new methods to generate $\mathrm{CoL}$, the kinetics of Co electrodeposition

*e-mail: hhuizar@uaeh.edu.mx has not been analyzed. Increased understanding of the nucleation and growth parameters involved during Co electrodeposition on Pt from chloride plating baths would allow the generation of Co films with reproducible characteristics and specific properties.

Recently, we reported a kinetic study of the formation of a Co monolayer on a Pt surface from an aqueous chloride solution $(\mathrm{pH}=$ 9.3) at underpotential conditions. ${ }^{16}$ It is important to mention that at this $\mathrm{pH}$ value, it is possible to neglect the influence of proton reduction during the analysis of Co electrodepostion. ${ }^{28}$ In addition, the previously reported formation of a Co monolayer on a Pt surface that modifies the nucleation and growth process at overpotential conditions must be considered. ${ }^{16}$ To the best of our knowledge, there is no information about the kinetics of Co electrodeposition from chloride solutions onto polycrystalline $\mathrm{Pt}$ at overpotential conditions. Therefore, to gain a deeper insight into this system, we investigated the kinetics of Co electrodeposition onto polycrystalline $\mathrm{Pt}$ from ammoniacal solutions at a basic $\mathrm{pH}$ and in a potential range that minimizes proton reduction.

\section{EXPERIMENTAL}

Co electrodeposition onto a Pt electrode from an aqueous solution containing $10^{-2} \mathrm{M} \mathrm{CoCl}_{2}$ and $1 \mathrm{M} \mathrm{NH}_{4} \mathrm{CI}$ at $\mathrm{pH} 9.3$ (adjusted with $\mathrm{NaOH})$ at $25{ }^{\circ} \mathrm{C}$ was investigated, as previously reported. ${ }^{16}$ Under these conditions, the main chemical species of the Co (II) ion was the $\left[\mathrm{Co}\left(\mathrm{NH}_{3}\right)_{5}\left(\mathrm{H}_{2} \mathrm{O}\right)\right]^{2+}$ complex..$^{28}$ The equilibrium potential for the $\left[\mathrm{Co}\left(\mathrm{NH}_{3}\right)_{5}\left(\mathrm{H}_{2} \mathrm{O}\right)\right]^{2+} / \mathrm{Co}^{0}$ redox system was determined as $-0.786 \mathrm{~V}$ vs $\mathrm{SCE}^{27}(-0.741 \mathrm{~V}$ vs $\mathrm{Ag} / \mathrm{AgCl}) .{ }^{16}$ All solutions were prepared using analytic grade reagents with ultrapure water (Millipore-Q system) and deoxygenated by bubbling with $\mathrm{N}_{2}$ for 15 min before each experiment. Once the solution was deoxygenated, a $\mathrm{N}_{2}$ atmosphere was maintained over the solution. The working electrode was a polycrystalline Pt rotating-disc electrode tip (geometric area 0.0314 $\mathrm{cm}^{2}$ ) provided by Radiometer Tacussel. The exposed surface of the disc was polished to a mirror finish with different alumina grades down to $0.05 \mu \mathrm{m}$ and cleaned ultrasonically. A graphite bar with an exposed area greater than the working electrode was used as a counter electrode. The reference electrode was a $\mathrm{Ag} / \mathrm{AgCl}$ electrode and all 
measured potentials were referred to this scale. The electrochemical experiments were conducted in a BAS $100 \mathrm{~W}$ potentiostat connected to a personal computer running the BAS100W software to control the experiments and collect data. To verify the electrochemical behavior of the electrode in the electrodeposition bath, a cyclic voltammetric study was performed in the [0.6 to -0.9$] \mathrm{V}$ potential range at 20 $\mathrm{mVs}^{-1}$. The kinetics of Co electrodeposition was studied under potentiostatic conditions through the analysis of the experimental current density transients obtained with the double potential step technique. The perturbation of the electrode potential always started at 0.600 $\mathrm{V}$. The first potential pulse was imposed at different potentials in the interval [ -0.742 to -0.773$] \mathrm{V}$. The second pulse (not shown) always ended at $0.600 \mathrm{~V}$.

\section{RESULTS AND DISCUSSION}

\section{Cyclic voltammetric study}

Figure 1 shows a cyclic voltammogram obtained for the $\mathrm{Pt} / 10^{-2}$ $\mathrm{M} \mathrm{CoCl}_{2}+1 \mathrm{M} \mathrm{NH}_{4} \mathrm{CI}$ system $(\mathrm{pH}=9.3)$ at a scan rate of $20 \mathrm{mVs}^{-1}$. The potential scan began at $0.6 \mathrm{~V}$, toward the negative potential -0.900 $\mathrm{V}$, and then reversed to the starting potential. During the direct scan, it was possible to identify four peaks, A, B, B', and C, at potential values of $-0.120,-0.425,-0.584$, and $-0.840 \mathrm{~V}$, respectively. Peak A corresponds to the supporting electrolyte, while peaks B and B' correspond to Co electrodeposition onto (100) and (111) crystallographic orientations, respectively, at underpotential conditions. ${ }^{16}$ Peak $\mathrm{C}$ may be related to Co electrodeposition at overpotential deposition (OPD) conditions. When the potential scan was inverted, a shoulder D and two anodic peaks, E and F, appeared at $-0.610,-0.410$, and 0.260 $\mathrm{V}$, respectively. The shoulder D and peaks $\mathrm{E}$ and $\mathrm{F}$ correspond to the dissolution of different Co phases.$^{28}$ In particular, peak F corresponds to the dissolution of the Co deposited at underpotential conditions. ${ }^{16}$ In a previous study, it was found that the processes corresponding peaks $\mathrm{B}, \mathrm{B}$ ', and $\mathrm{C}$ followed a diffusional control. ${ }^{16}$ In the observed potential range, the voltammetric curves showed the presence of a drastic slope change after peak $\mathrm{C}$, at approximately $-0.900 \mathrm{~V}$. In general, this process corresponds to proton reduction. To detect the potential at which proton reduction is negligible in comparison to Co electrodeposition, we conducted a set of voltammetric studies at different inversion potentials $\left(E_{\lambda}\right)$. The results are summarized in Table 1 . Note that, at potentials more positive than $-0.900 \mathrm{~V}$, the ratio cathodic to anodic charge $\left(\mathrm{Q}_{\mathrm{c}} / \mathrm{Q}_{\mathrm{a}}\right)$ is close to 1 . These results indicate that proton reduction is minimized at $E_{\lambda}>-0.860 \mathrm{~V}$. Moreover, it may be observed that in the potential range analyzed in this study, proton reduction may be negligible.

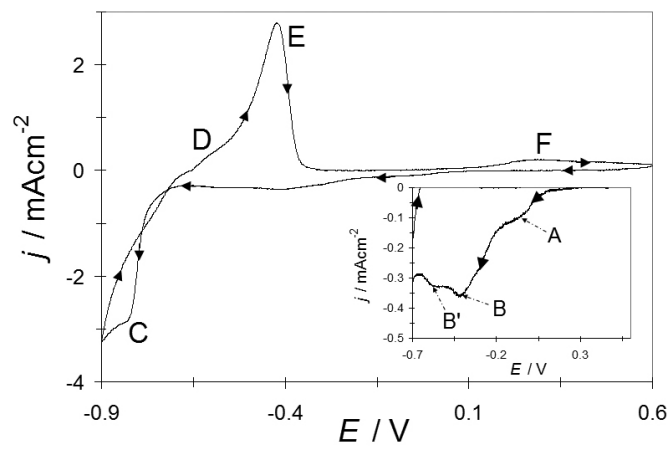

Figure 1. Cyclic voltammogram obtained in the $\mathrm{Pt} / 1 \mathrm{O}^{-2} \mathrm{M} \mathrm{CoCl}_{2}+1 \mathrm{M} \mathrm{NH}_{4} \mathrm{Cl}$ (pH 9.3) system. The potential scan started at $0.600 \mathrm{~V}$ with a potential scan rate of $20 \mathrm{mVs}^{-1}$. Arrows indicate the potential scan direction. Cathodic (A, B, $B$ ', and $C)$ and anodic ( $D, E$, and $F)$ current density peaks are also indicated
Table 1. Comparison between the cathodic and anodic charges at different inversion potentials $\left(E_{\lambda}\right)$ obtained from the aqueous solution containing $0.01 \mathrm{M} \mathrm{CoCl}_{2}+1 \mathrm{M} \mathrm{NH}_{4} \mathrm{CI}$ system $(\mathrm{pH}=9.3)$

\begin{tabular}{ll}
\hline$-E_{\lambda} / \mathrm{V}$ & $\mathrm{Q}_{\mathrm{c}} / \mathrm{Q}_{\mathrm{a}}$ \\
\hline 0.900 & 1.127 \\
0.860 & 1.048 \\
0.820 & 1.028 \\
0.810 & 1.016 \\
0.790 & 1.006 \\
0.780 & 1.009 \\
0.760 & 1.002 \\
0.750 & 0.997 \\
\hline
\end{tabular}

\section{Kinetic analysis of the $3 D$ nucleation and growth process}

The formation of new phases occurs through nucleation and growth mechanisms, and the corresponding current transients can provide detailed information about the electrocrystallization process. Figure 2 shows the characteristic current density transients obtained at the OPD region $(E \leq-0.742 \mathrm{~V})$. For clarity, we have plotted the transients recorded in two intervals $[-0.742$ to -0.759$] \mathrm{V}$ and $[-0.760$ to -0.773$] \mathrm{V}$, as seen in Figures $2 \mathrm{a}$ and $2 \mathrm{~b}$, respectively. In Figure 2a, the presence of a maximum M1 at $-0.742 \mathrm{~V}$ is evident. Seemingly, the general shape of these transients is similar to those reported for a three-dimensional (3D) nucleation and growth process with diffusional control. In addition, in the second interval, another peak is observed. The maxima M1 and M2 are slightly displaced at lower times as the applied potential is more negative. In the literature, the presence of multiple maxima in a transient corresponds to three different mechanisms. The first, proposed by Abyaneh et al., is related to a death and rebirth of centers ${ }^{29}$ the second suggests the existence of different macroscopic zones on the electrode surface, ${ }^{30}$ and the third is related to nucleation from different chemical species. In this study, the presence of death and rebirth of centers was discarded because the second maximum appears at lower times than the first, contrary to the result predicted by Abyaneh's theory. ${ }^{29}$ Palomar-Pardave et al. showed that, under our experimental conditions, the predominant chemical species is aminocomplex. ${ }^{26}$ Moreover, if Co is considered to be present in two possible oxidation states in solution $\mathrm{Co}$ (II) and $\mathrm{Co}(\mathrm{III})$, a transfer charge $\mathrm{Co}(\mathrm{III}) \rightarrow \mathrm{Co}(\mathrm{II})$ prior to electrodeposition may exist. ${ }^{16}$ However, in a previous study, we showed that this step did not appear under our experimental conditions, because it occurred at potential values more positive than those studied here. ${ }^{16}$ Thus, Co electrodeposition occurs through the same chemical species. In addition, in a previous study, through reflectance diffuse spectroscopy and theoretical quantum studies, we showed that the polycrystalline Pt electrode exhibits two main crystallographic orientations on the Pt surface. This suggests the presence of two zones where two simultaneous 3D nucleation and growth processes may occur. This situation should be verified using a microscopic study on single $\mathrm{Pt}$ crystals to separate the overlapped processes; however, this analysis is beyond the scope of this study. Although similar transients with complex shapes, as shown in Figure 2b, have been reported for the electrodeposition of $\mathrm{Bi}$ and $\mathrm{Ag}$ on $\mathrm{Pt},{ }^{30,31}$ such transients have not been analyzed to determine kinetic parameters that describe the nucleation and growth process. ${ }^{30}$ In all the transients depicted in Figure 2, an extended falling current at initial times can be observed. This current has been related to a partial double-layer contribution and a Co underpotential deposition (UPD) process onto a Pt electrode. ${ }^{16}$ Under these circumstances, the Co deposition at overpotential conditions begins on a previously formed Co monolayer on the Pt surface. ${ }^{16}$ 
Thus, a Co UPD-OPD transition during Co electrodeposition onto this electrode is expected.
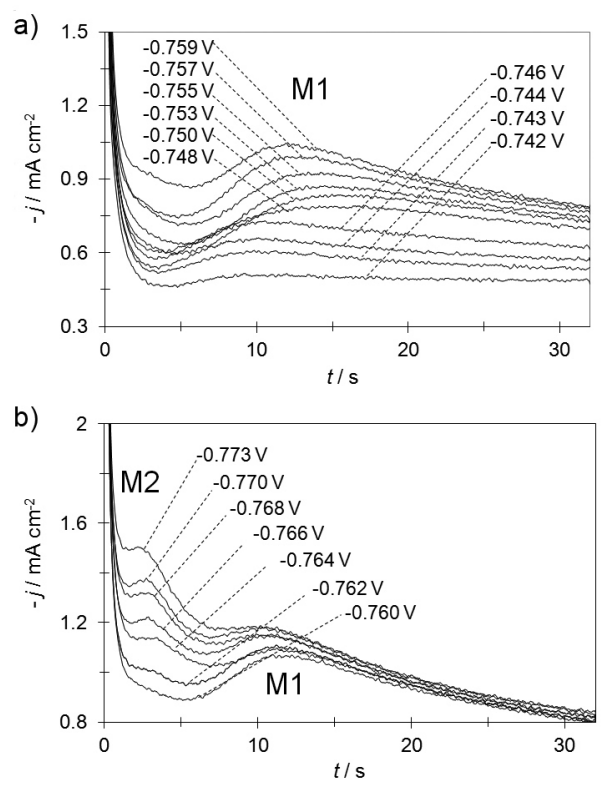

Figure 2. Set of experimental current transients recorded in the $\mathrm{Pt} / 10^{-2} \mathrm{M}$ $\mathrm{CoCl}_{2}+1 \mathrm{M} \mathrm{NH}_{4} \mathrm{Cl}(\mathrm{pH} 9.3)$ system. In all cases, the starting potential applied was $0.600 \mathrm{~V}$. For $0<t \leq 32 \mathrm{~s}$, it was applied as a different negative potential step, as indicated in the figure

In accordance with the results from a previous study ${ }^{16}$ and the evidence presented in this paper, we conclude that four processes are involved during Co electrodeposition at overpotential conditions on a Pt electrode. Therefore, we propose a model that predicts the general behavior of these transients:

$$
j_{\text {total }}(t)=j_{\mathrm{a}-\mathrm{d}}(t)+j_{2 \mathrm{D}-\mathrm{i}}(t)+j_{3 \mathrm{D}-\mathrm{dc}(\mathrm{M} 1)}(t)+j_{3 \mathrm{D}-\mathrm{dc}(\mathrm{M} 2)}(t)
$$

where $j_{\mathrm{a}-\mathrm{d}}(t)$ and $j_{2 \mathrm{D}-\mathrm{i}}(t)$ correspond to the processes identified in the initial current fall decay, ${ }^{16}$ and $j_{3 \mathrm{D}-\mathrm{da}\left(\mathrm{M}_{1}\right)}(t)$ and $j_{3 \mathrm{D}-\mathrm{dc}\left(\mathrm{M}_{2}\right)}(t)$ correspond to the 3D nucleation and growth processes associated to peaks M1 and $\mathrm{M} 2$, respectively. $j_{\mathrm{a}-\mathrm{d}}(t)$ is the current density for a Langmuir-type adsorption-desorption process and is given as follows: ${ }^{32}$

$$
j_{\mathrm{a}-\mathrm{d}}(t)=k_{1} \exp \left(-k_{2} t\right)
$$

while $j_{2 \mathrm{D}-\mathrm{i}}(t)$ is the current density corresponding to a diffusion-controlled instantaneous two-dimensional nucleation mechanism: ${ }^{33}$

$$
j_{2 D-i}(t)=k_{3} \exp \left(-k_{4} t\right)
$$

$k_{1}=k_{2} Q_{\text {ads }}$ and $Q_{\text {ads }}$ is the charge density due to adsorption..$^{32}$ After the initial current fall, the current recorded for processes M1 and M2 is given as follows: ${ }^{34}$

$$
\begin{aligned}
& j_{3 D-d c\left(M_{i}\right)}(t)=z F D c \frac{1}{\left(\pi D(t)^{1 / 2}\right)} \\
& \times\left\{1-\exp \left[-\alpha N_{0, M_{i}}\left(\pi D t^{2}\right)^{1 / 2}\left[1-\left(\frac{1-\exp \left(A_{M_{i}} t\right)}{A_{M_{i}} t}\right)\right]\right]\right\}
\end{aligned}
$$

where $F$ is the Faraday's constant, $\mathrm{z}$ is the number of transferred electrons, $A_{M_{i}}$ is the nucleation rate, $N_{0, M_{i}}$ is the number of active nucleation sites, and $D$ is the diffusion coefficient for process $M_{i}$.
Figure 3 shows a comparison of two experimental current density transients with the theoretically generated curves obtained by nonlinear fitting of the experimental data to Eq. (1). Note that the model expressed by this equation adequately predicts the behavior of the entire experimental current density transients. In the fitting shown in Figure $3 \mathrm{a}(-0.753 \mathrm{~V})$, it is possible to observe the charge corresponding to M2; this charge is lower in comparison to that corresponding to M1. A contrary situation may be observed from the fitting depicted in Figure $3 b(-0.768 \mathrm{~V})$, where the charge corresponding to M2 is larger. These results suggest that, in the potential range $[-0.742$ to $-0.759] \mathrm{V}, \mathrm{M} 1$ is favored, while in the second potential range [ -0.760 to -0.773$] \mathrm{V}, \mathrm{M} 2$ is predominant. The values $\mathrm{k}_{1}=0.048 \mathrm{~mA} \mathrm{~cm}^{-2}, \mathrm{k}_{2}=$ $5.25 \mathrm{~s}^{-1}, \mathrm{k}_{3}=0.046 \mathrm{~mA} \mathrm{~cm}{ }^{-2}$, and $\mathrm{k}_{4}=0.038 \mathrm{~s}^{-1}$ remained almost constant in all fittings. These values are similar to those reported for the UPD of Co onto polycrystalline Pt. ${ }^{16}$ The 3D nucleation and growth parameters obtained for the transients depicted in Figure 2 are reported (Table 2). From the fittings, the average diffusion coefficient values calculated for M1 and M2 were $3.06 \times 10^{-6} \mathrm{~cm}^{2} \mathrm{~s}^{-1}$. It can be observed that, at lower overpotentials, the nucleation rate values for $\mathrm{M} 1, A(\mathrm{M} 1)$, were larger than those for M2, A(M2). However, note that the $A(\mathrm{M} 2)$ values increased when the applied overpotential was larger, and from $-0.762 \mathrm{~V}, A(\mathrm{M} 2)$ were significantly larger than $A(\mathrm{M} 1)$. Moreover, Figure 3 shows that M2 starts prior to M1, and when M1 has started, $j_{2 \mathrm{D}-\mathrm{i}}(t)$ ended, and $j_{3 \mathrm{D}-\mathrm{dc}(\mathrm{M} 2)}(t)$ is the predominant process. In addition, it may be observed that, when the applied overpotential is more negative than $0.762 \mathrm{~V}, \mathrm{M} 2$ was particularly favored. The number of active nucleation sites available for each process is reported (Table 2). Note that larger values were obtained for M2 in comparison to M1. This behavior suggests M2 is favored for the second potential range.
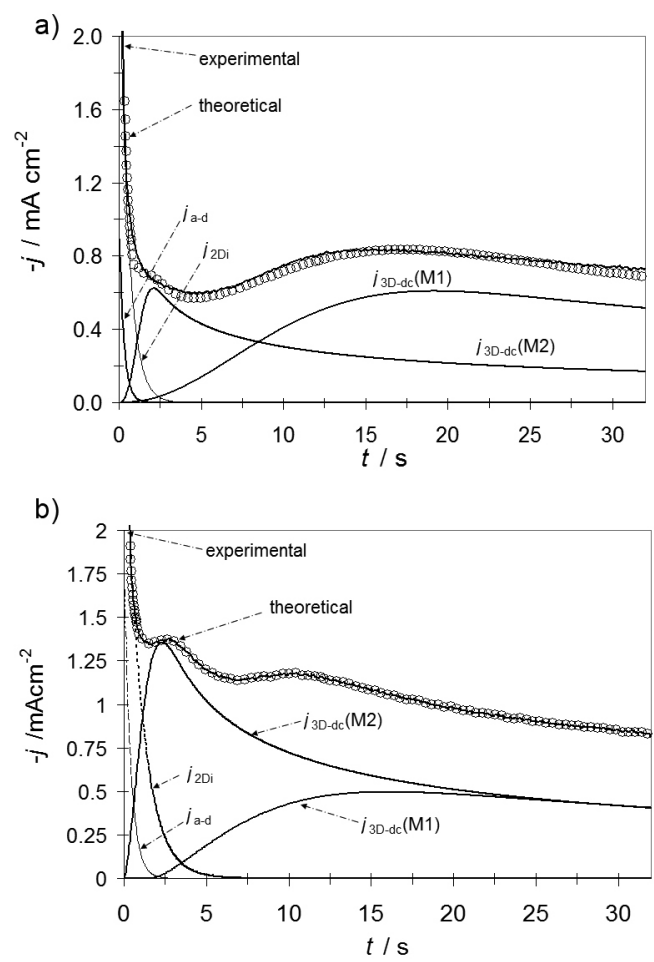

Figure 3. Comparison of two experimental current density transients (o o o) recorded during Co OPD process at a) $-0.753 \mathrm{~V}$ and $b)-0.768 \mathrm{~V}$ and a theoretical transient (-) obtained by nonlinear fitting of Eq. (1) to the experimental data

\section{Analysis of the kinetic parameters}

From the nucleation and growth parameters obtained (Table 2), 
Table 2. Potential dependence observed for the nucleation parameters during cobalt deposition from the system $\mathrm{Pt} / 0.01 \mathrm{M} \mathrm{CoCl}_{2}+1 \mathrm{M} \mathrm{NH}_{4} \mathrm{CI}$ system $(\mathrm{pH}=9.3)$. The values were obtained from best-fit parameters of the experimental $j$ - $t$ plots using Eq. (1)

\begin{tabular}{ccccc}
\hline$-E / \mathrm{V}$ & $\begin{array}{c}A(\mathrm{M} 1) / \\
\mathrm{s}^{-1} \mathrm{~cm}^{-2}\end{array}$ & $\begin{array}{c}A(\mathrm{M} 2) / \\
\mathrm{s}^{-1} \mathrm{~cm}^{-2}\end{array}$ & $\begin{array}{c}N(\mathrm{M} 1) \times 10^{-5} / \\
\mathrm{cm}^{-2}\end{array}$ & $\begin{array}{c}N(\mathrm{M} 2) \times 10^{-5} / \\
\mathrm{cm}^{-2}\end{array}$ \\
\hline 0.742 & 0.400 & 0.150 & 0.03 & 1.56 \\
0.743 & 0.400 & 0.170 & 0.11 & 2.86 \\
0.744 & 0.410 & 0.192 & 0.13 & 5.81 \\
0.746 & 0.420 & 0.210 & 0.11 & 6.82 \\
0.750 & 0.433 & 0.260 & 0.39 & 15.18 \\
0.753 & 0.447 & 0.343 & 0.26 & 15.40 \\
0.755 & 0.460 & 0.399 & 0.28 & 16.07 \\
0.757 & 0.465 & 0.492 & 0.34 & 24.92 \\
0.759 & 0.465 & 0.595 & 0.43 & 23.97 \\
0.760 & 0.470 & 0.638 & 0.42 & 26.33 \\
0.762 & 0.470 & 1.000 & 0.47 & 29.60 \\
0.764 & 0.470 & 1.300 & 0.69 & 28.45 \\
0.766 & 0.517 & 1.710 & 0.72 & 23.73 \\
0.768 & 0.498 & 1.880 & 0.65 & 27.52 \\
0.770 & 0.530 & 2.600 & 0.66 & 28.20 \\
0.773 & 0.677 & 3.520 & 0.77 & 34.98 \\
\hline
\end{tabular}

it is possible to calculate the saturation number of nuclei $\left(N_{\mathrm{s}}\right)$ (Table 3). The $N_{\mathrm{s}}$ values were calculated using Eq. (5): ${ }^{35}$

$$
N_{S}=\left(\frac{A N_{0}}{2 k^{\prime} D}\right)^{1 / 2}
$$

where

$$
k^{\prime}=\frac{4}{3}\left(\frac{8 \pi C_{o} M}{\rho}\right)^{1 / 2}
$$

Note that the $N_{\mathrm{s}}$ values increased with the applied overpotential. Here it is noteworthy that due to the exclusion zones caused by the hemispherical diffusional gradients of the $3 \mathrm{D}$ nucleus, the $N_{\mathrm{s}}$ values will be lower than the $N_{0}$ values at the same potential. In addition, it is possible to define the $N_{\mathrm{s}} / N_{0}$ ratio as a measurement of the efficiency of the use of available nucleation sites on the surface. Note that the $N_{s} / N_{0}$ ratio in all cases is larger for M1 than that for M2, which indicates that M1 is more efficient than M2. However, note that the $N_{\mathrm{s}}(\mathrm{M} 2)$ values are considerably larger in comparison with the $N_{\mathrm{s}}(\mathrm{M} 1)$ values. On average, the ratio $N_{\mathrm{s}}(\mathrm{M} 2) / N_{\mathrm{s}}(\mathrm{M} 1)$ was 9 , which suggests that M2 is favored.

From the nucleation rate values, it is possible to calculate the number of atoms that form the critical nucleus by employing the atomistic theory of electrolytic nucleation, ${ }^{36,37}$ using Eq. (7): ${ }^{37}$

$$
n_{\mathrm{c}}=\frac{k_{B} T}{z e_{\mathrm{o}}} \frac{\mathrm{d} \ln A}{\mathrm{~d} \eta}-\alpha
$$

In this equation, $k_{\mathrm{B}}$ is the Boltzmann constant $\left(1.38066 \times 10^{-23}\right.$ $\left.\mathrm{J} \mathrm{mol}^{-1}\right), T$ is the absolute temperature, $z$ is the number of transferred electrons, and $e_{\mathrm{o}}$ is the elementary electric charge. Substituting $\alpha=0.5$ and the values of the slopes $\operatorname{dln} A(\mathrm{M} 1) / d \eta \approx 11.63$ and $\operatorname{d} \ln A(\mathrm{M} 2) / d \eta \approx 101.22$ in Eq. (7), obtained from the experimental dependence of $\ln A v s \eta$ (Figure 4), $n_{\mathrm{c}}=0$ for M1 and $n_{\mathrm{c}}=1$ for M2 are obtained. A value of $n_{c}=0$ indicates that each active site on the Pt electrode surface acts as a critical nucleus, while $n_{c}=1$ indicates that the critical nucleus is formed by one Co atom..$^{23,24,38}$ These results suggest different energetic zones on the polycrystalline surface, which is coincident with previous results. ${ }^{16,39}$

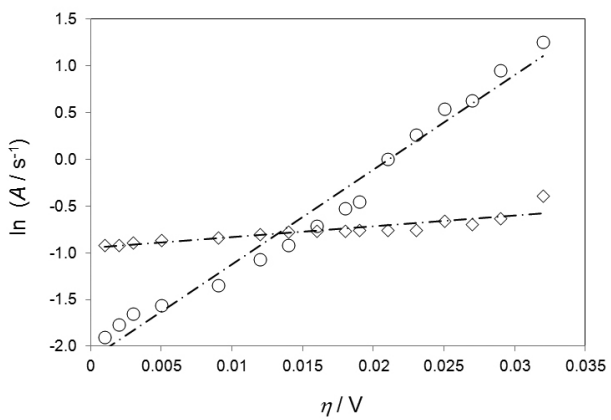

Figure 4. InA vs $\eta$ plot, used to calculate the critical size of Co nucleus according to Eq. (7). The broken straight line corresponds to the linear fit of the experimental data

\begin{tabular}{|c|c|c|c|c|c|}
\hline$-E / V$ & $N_{s}(\mathrm{M} 1) \times 10^{-5} / \mathrm{cm}^{-2}$ & $N_{S}(\mathrm{M} 2) \times 10^{-5} / \mathrm{cm}^{-2}$ & $\mathrm{Ns} / N_{0}(M 1)$ & $\mathrm{Ns} / N_{0}(M 2)$ & $N_{S}(\mathrm{M} 2) / N_{S}(\mathrm{M} 1)$ \\
\hline 0.742 & 0.019 & 0.085 & 0.63 & 0.05 & 4.5 \\
\hline 0.743 & 0.037 & 0.122 & 0.34 & 0.04 & 3.3 \\
\hline 0.744 & 0.040 & 0.185 & 0.31 & 0.03 & 4.6 \\
\hline 0.746 & 0.038 & 0.209 & 0.35 & 0.03 & 5.5 \\
\hline 0.750 & 0.072 & 0.355 & 0.18 & 0.02 & 4.9 \\
\hline 0.753 & 0.060 & 0.402 & 0.23 & 0.03 & 6.7 \\
\hline 0.755 & 0.063 & 0.443 & 0.23 & 0.03 & 7.0 \\
\hline 0.757 & 0.070 & 0.613 & 0.21 & 0.02 & 8.8 \\
\hline 0.759 & 0.078 & 0.661 & 0.18 & 0.03 & 8.5 \\
\hline 0.760 & 0.078 & 0.717 & 0.19 & 0.03 & 9.2 \\
\hline 0.762 & 0.082 & 0.952 & 0.17 & 0.03 & 11.6 \\
\hline 0.764 & 0.100 & 1.065 & 0.14 & 0.04 & 10.7 \\
\hline 0.766 & 0.107 & 1.115 & 0.15 & 0.05 & 10.4 \\
\hline 0.768 & 0.100 & 1.259 & 0.15 & 0.05 & 12.6 \\
\hline 0.770 & 0.104 & 1.499 & 0.16 & 0.05 & 14.4 \\
\hline 0.773 & 0.126 & 1.942 & 0.16 & 0.06 & 15.4 \\
\hline
\end{tabular}

Table 3. Potential dependence of $N_{\mathrm{s}}$ from aqueous solution containing $0.01 \mathrm{M} \mathrm{CoCl}_{2}+1 \mathrm{M} \mathrm{NH}_{4} \mathrm{CI}$ system (pH=9.3) calculated from physical constants reported in Table 2 and Eq. (5) 
In addition, it is possible to calculate the Gibbs free energy of nucleation using Eq. (8): $:^{40-42}$

$$
A=k_{3} \exp \left(-\frac{\Delta G}{k_{B} T}\right)=k_{3} \exp \left(-\frac{k_{4}}{\eta^{2}}\right)
$$

Here $\Delta G$ is the Gibbs free energy of nucleation (Jnucleus ${ }^{-1}$ ); $k_{3}=N_{0} \omega_{n_{+c}} \Gamma$, where $\omega_{n_{+c}}$ is the frequency of attachment of single atoms to the critical nucleus and $\Gamma$ is the nonequilibrium Zeldovich factor that exponentially depends on overpotential. ${ }^{43}$ On the other hand, $k_{4}=-\left(16 \pi \gamma^{3} M^{2} \phi(\theta) / 3 \rho^{2} z^{2} F^{2} k T\right)$, where $\gamma$ is the interfacial tension between the nucleus and its mother phase and $\phi(\theta)$ is a function of the contact angle $\theta$ between the nucleus and substrate. ${ }^{43}$ To calculate the value of the Gibbs free energy, a $\ln A v s \eta^{-2}$ plot can be constructed according to Eq. (9), and $\Delta G$ could be calculated from the slope $k_{5}$ of the linear relationship:

$$
\left(-\frac{\Delta G}{K_{B} T}\right)=\frac{k_{5}}{\eta^{2}}
$$

Note that the plot $\ln A$ vs $\eta^{-2}$ plot showed two linear zones; the inflexion point was detected at the potential value of $-0.757 \mathrm{~V}$ (Figure 5). For M1, the slope values were $8 \times 10^{-6}$ and $2 \times 10^{-4}$ for the first and second zones, respectively. For M2, the slope values were $9 \times$ $10^{-5}$ and $9 \times 10^{-4}$ for the first and second zones, respectively. The average $\Delta G$ calculated at different potentials was $0.728 \times 10^{-21}$ and $2.7 \times 10^{-21}$ Jnucleus $^{-1}$ for M1 and M2, respectively. These energies correspond to the $\Delta G$ value requirements for the formation of a stable nucleus for each process. ${ }^{44,45}$

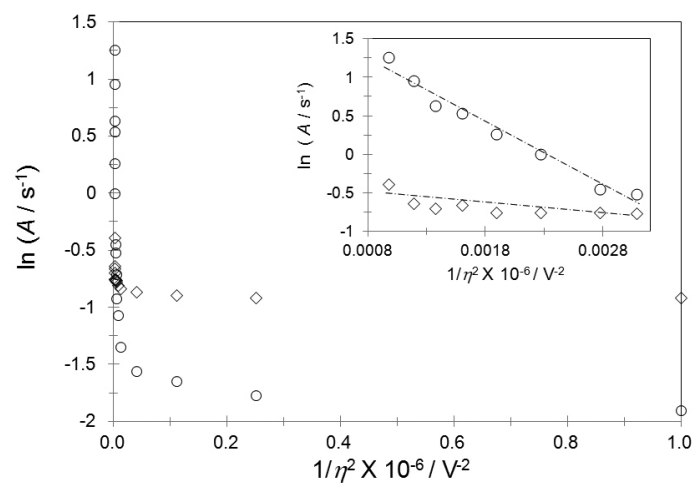

Figure 5. InA vs $\eta^{-2}$ plot, used to calculate the Gibbs free energy of nucleation according to Eq. (9). The broken straight line corresponds to the linear fit of the experimental data

\section{CONCLUSIONS}

Co electrodeposits onto polycrystalline Pt were studied at OPD conditions from an aqueous solution. In the OPD zone, the transients showed complex shapes that involved the overlap of a 2D instantaneous nucleation and two 3D nucleation and growth processes. The results obtained suggest the presence of two predominant crystallographic orientations on the Pt surface, which causes the appearance of two 3D nucleation and growth processes. In the potential range studied, the $N_{0}$ and $N_{\mathrm{s}}$ values were larger for M2 than for M1, indicating different energetic conditions on the electrode surface.

\section{ACKNOWLEDGMENTS}

CHRR thanks to CONACyt for conferring a postdoctoral fellowship. LHMH gratefully acknowledges financial support from the Universidad Autónoma del Estado de Hidalgo. LHMH and CHRR are grateful for the stipends received from SNI (México).

\section{REFERENCES}

1. Gauthier, Y.; Dolle, P.; Boudoing-Savois, R.; Hebestrein, W.; Platzgummer, E.; Schmid, M.; Varga, P.; Surf. Sci. 1998, 396, 137.

2. Lunggren, E.; Alvarez, J.; Torelles, X.; Peters, K.F.: Isern, H.; Ferrer, S.; Phys. Rev. B 1999, 59, 2431.

3. Platzgummer, E.; Sporn, M.; Koller, R.; Schmid, M.; Hofer, W.; Varga, P.; Surf. Sci. 2000, 453, 214.

4. Varga, P.; Schmid, M.; Appl. Surf. Sci. 1999, 141, 287.

5. Aden-Broeder, F. J.; Hoving, W.; Bloemen, P. J. H.; J. Magn. Magn. Mater. 1991, 93, 562.

6. Smardz, L.; Szymanski, B.; Gontarz, R.; Stefanski, P.; Barnas, J.; J. Magn. Magn. Mater. 1993, 120, 239.

7. Spörl, K.; Weller, D.; J. Magn. Magn. Mater. 1991, 93, 379.

8. Kitada, M.; Shimizu, N.; J. Appl. Phys. 1983, 54, 7089.

9. Rafaja, D.; Vacínová, J.; Valvoda, V.; Thin Solid Films, 2000, 374, 10.

10. Rafaja, D.; Chládek, M.; Valvoda, V.; Seddat, M.; Lassri, H.; Krishnan, R.; Thin Solid Films 1997, 292, 61.

11. Myung, N.; Ryu, K. H.; Sumodjo, P. T. A.; Nobe, K. In Proceedings of the Symposium on 'Fundamental Aspects of Electrochemical Deposition and Dissolution Including Modeling'; Paunovic, M.; Datta, M.; Matosz, M.; Osaka, T.; Talbot, J. B., eds.; Electrochemical Society, Inc.: Pennington, 1998, p. 136.

12. Kongstein, O. E.; Haarberg, G. M.; Thonstad, J.; J. Appl. Electrochem. 2007, 37, 669.

13. Kongstein, O. E.; Haarberg, G. M., Thonstad, J.; J. Electrochem. Soc. 2010, 157, D335.

14. Georgescu, V.; Georgescu, M.; Surf. Sci. 2002, 507, 507.

15. Georgescu V.; Mazur, V.; Pushcashu B.; Mat. Sci. Eng. B 2000 68,131.

16. Mendoza-Huizar, L. H.; Rios-Reyes, C. H.; J. Solid. State. Electrochem. 2011, 15, 737.

17. Sahari, A.; Azizi, A.; Fenineche, N.; Schmerber, G.; Dinia, A.; Surf. Rev. Lett. 2005, 12, 391.

18. Bento, F. R.; Mascaro, L. H.; J. Braz. Chem. Soc. 2002, 13, 502.

19. Santos, J. S.; Trivinho-Strixino, F.; Pereira, E. C.; Surf. Coat. Tech. 2010, $205,2585$.

20. Santos, J. S.; Matos, R.; Trivinho-Strixino, F.; Pereira, E. C.; Electrochim. Acta 2007, 53, 644.

21. Matsushima, J. T.; Trivinho-Strixino, F.; Pereira, E. C.; Electrochim. Acta 2006, 51, 1960.

22. Fujimori, M.; Ono, N.; Tamura, N.; Kohga, T. In Chloride Electrometallurgy; Parker, P. D., ed.; The Metallurgical Society: Warrendale, 1982, p. $155-166$.

23. Mendoza-Huizar, L. H.; Palomar-Pardave, M.; Robles, J.; Electrochim. Acta 2001, 46, 2749.

24. Mendoza-Huizar, L. H.; Robles, J.; Palomar-Pardavé, M.; J. Electroanal. Chem. 2002, 521, 95.

25. Cagnon, L.; Gundel, A.; Devolder, T.; Morrone, A.; Chappert, C.; Schmidt, J.E., Allongue, P.; Appl. Surf. Sci. 2000, 164, 22.

26. Bao, Z. L.; Kavanaugh, K. L.; J. Cryst. Growth. 2006, 287, 514.

27. Grujicic, D.; Pesic B.; Electrochim. Acta 2004, 49, 4719.

28. Palomar-Pardavé, M.; González, I.; Soto, A. B.; Arce, E. M.; J. Electroanal. Chem. 1998, 443, 125.

29. Abyaneh, M. Y.; Visscher, W.; Barendrecht, E.; Electrochim. Acta 1983, $28,285$.

30. Kapocius, V.; Gudaviciuté, L.; Karpaviciené, V.; Steponavicius, A.; Chemija (Vilnius) 2001, 12, 125.

31. Hernández, N.; Ortega, J. M.; Choy, M.; Ortiz, R.; J. Electroanal. Chem. 2001, 515, 123. 
32. Hözle, M. H.; Retter, U.; Kolb, D. M.; J. Electroanal. Chem. 1994, 371, 101.

33. Amstrong, R. D.; Harrison, J. A.; J. Electrochem. Soc. 1969, 116, 328.

34. Scharifker, B. R.; Mostany; J.; Journal of Electroanalytical Chemistry and Interfacial Electrochemistry 1984, 177, 13.

35. Scharifker, B. R.; Hills, G.; Electrochim Acta. 1983, 28, 879.

36. Milchev, A.; Stoyanov, S.; Kaischev, R.; Thin Solid Films 1974, 22, 255.

37. Milchev, A.; Contemp. Phys. 1991, 32, 321.

38. Arbib, M.; Zhang, B.; Lazarov, V.; Stoychev, D.; Milchev, A.; BuessHerman, C.; J. Electroanal. Chem. 2001, 510, 67.

39. Mendoza-Huizar, L. H.; Robles, J.; Palomar-Pardave, M.; J. Electrochem. Soc. 2005, 152, C265.
40. Southampton Electrochemistry Group; Instrumental Methods in Electrochemistry, Wiley: New York, 1985, p. 923.

41. Mostany, J.; Mozota, J.; Scharifker, B. R.; J. Electroanal. Chem. 1984, $177,25$.

42. Serruya, A.; Mostany, J.; Scharifker, B. R.; J. Electroanal. Chem. 1999, $464,39$.

43. Milchev, A.; Electrocrystallization: Fundamentals of nucleation and growth, Kluwer Academic Publishers: Massachusetts, 2002, ch. 2.2.3.

44. Myland, J.C.; Oldham, K.B.; J. Electroanal. Chem. 2005, 575, 81.

45. Zhu, C. Y.; Wu, R.; Wu, Y. Q.; Fan, Y. L.; Jiang, Z. M.; Yang, X. J.; Nanotechnology 2007, 18, 235403. 